Haya: The Saudi Journal of Life Sciences

Abbreviated Key Title: Haya Saudi J Life Sci

ISSN 2415-623X (Print) |ISSN 2415-6221 (Online)

Scholars Middle East Publishers, Dubai, United Arab Emirates

Journal homepage: https://saudijournals.com

Original Research Article

\title{
The Loss of Smell and Taste in the COVID-19 Outbreak, A Cross Sectional Study
}

\author{
Ghazanfar $\mathrm{Ali}^{1}$, Naheed Akhter ${ }^{2}$, Rabia Akram ${ }^{3}$, Syed Asif Jahanzeb Kazmi ${ }^{4}$, Mahwash Saleem Khan ${ }^{5}$, Saba Iqbal ${ }^{6 *}$ \\ ${ }^{1}$ Assistant Professor Pulmonology, CMH Institute of Medical Sciences, Bahawalpur Pakistan \\ ${ }^{2}$ Assistant Professor Medicine, CMH Institute of Medical Sciences, Bahawalpur Pakistan \\ ${ }^{3}$ Assistant Professor Gynaecology and obstetrics, Shalamar Medical \& Dental College, Lahore Pakistan \\ ${ }^{4}$ Professor \& HOD of Pharmacology, CMH Institute of Medical Sciences, Bahawalpur Pakistan \\ ${ }^{5}$ Senior lecturer DHPE, CMH Lahore Medical College \& IOD, Lahore Pakistan \\ ${ }^{6}$ Assistant Professor DHPE, CMH Lahore Medical College \& IOD, Lahore Pakistan
}

DOI: $10.36348 /$ sjls.2022.v07i01.005 | Received: 16.12.2021 | Accepted: 21.01 .2022 | Published: 28.01 .2022

*Corresponding author: Dr. Saba Iqbal

Assistant Professor DHPE, CMH Lahore Medical College \& IOD, Lahore Pakistan

\section{Abstract}

Background: A significant proportion of people infected with COVID-19 report new onset of smell and taste loss. The duration of the chemosensory impairment and prognostic factors of recovery is still unclear. We aimed to investigate the prevalence rate and other signs and symptoms which are predictors in patients. Objective: To find out the association of Anosmia and Ageusia with COVID-19. To find out relationship of Gender with Anosmia and Ageusia in COVID-19 or other URTI. Methods: I was a cross-sectional study, participants were from CMH, Multan, Hospitals of different cities of the province of Punjab, Pakistan. The study was conducted from 1st July to 31st of August 2021. 185. All faculty members and medical Students of CMH Bahawalpur. Results: Out of 185 participants, 99 (53.5\%) were male and 86 $(46.5 \%)$ were female. The mean age was $23.93 \pm 6.661$ years. Pearson correlation of covid-19 with loss of smell is 0.533 which shows that there is strong positive relationship between them. On one-way ANOVA fever sig. is 0.002 which shows high significance. URTI also shows association but other signs and symptoms like dyspnoea, dry cough do not show any significance. Shows the majority of participants are suffering from taste and smell loss (95.1\%) along with body aches (82.7\%), dyspnoea (94.6\%), acute dry cough (36.2\%), URTI (19.5\%) and fever (36.2\%).

Keywords: Olfactory dysfunction; coronavirus disease-2019; COVID-19; Ageusia; anosmia; post-viral; recovery; gustatory dysfunction; chemosensory loos.

Copyright $\odot \mathbf{2 0 2 2}$ The Author(s): This is an open-access article distributed under the terms of the Creative Commons Attribution 4.0 International License (CC BY-NC 4.0) which permits unrestricted use, distribution, and reproduction in any medium for non-commercial use provided the original author and source are credited.

\section{INTRODUCTION}

During different waves of Covid illness 2019 (SARS-CoV-2) pandemic, COVID-19 enters your body through our mouth, nose or eyes. The virus travels to the back of our nasal passages and mucous membrane in the back of your throat. It attaches to cells there, begins to multiply and moves into lung tissue. From there, the virus can spread to other body tissues. Early observations in China were revealed several nonspecific signs and symptoms related to COVID-19 infection, including fever, dry cough, dyspnea, myalgia, and anorexia. Other symptoms include muscle and joint pain, sore throat, headache, nausea or vomiting, diarrhea, and some nasal symptoms [1]. Many examinations have shown that a huge extent of individuals who test positive for COVID-19 have an onset of Ageusia (loss of taste) or Anosmia (loss of smell) [2]. The Centers for Disease Control and Prevention, the WHO (World Health Organization), and NCOC (National Command and Operation Centre) added 'new loss of taste and smell' to the list of symptoms related to COVID-19. A surge in patients seeking medical advice for recent onset of selfdiagnosed loss of sense of taste and smell have been reported [3].

Pathway of smell is the nasal airflow odorants reach the olfactory neuro-epithelium which covers a surface of $8-10 \mathrm{~cm} 2$ of the olfactory cleft in the upper part of the nasal cavities and they were activate the olfactory receptor (OR) proteins. The olfactory neuroepithelium contains approx. 5-30 million receptor neurons which express up to 350 different OR. On the 
Ghazanfar Ali et al., Haya Saudi J Life Sci, Jan, 2022; 7(1): 24-28

other side, the sense of taste is conveyed through only 5 taste receptors (sweet, salted, bitter, sour, umami) expressed in the tongue and palate gustatory buds [4].

The post-viral etiology being also the most frequent cause of permanent loss of smell. Major causes of acquired anosmia include upper respiratory tract infections (URTI) by respiratory viruses (adenovirus, coronavirus, rhinovirus), influenza, brain injury, upper airway inflammation (rhinitis, rhino sinusitis), and neurodegenerative (Parkinson and Alzheimer) diseases while minor causes are intracranial/ Sino-nasal tumors, drugs, exposure to toxic substances, irradiation, or allergic factors [5].

Post-viral infection anosmia is one of the important symptoms of loss of sense of smell, accounting for up to $40 \%$ cases of anosmia [6]. Viruses that give rise to the common cold are well known to cause post-infectious loss. Previously described coronaviruses are supposed to account for $10-15 \%$ cases. It is therefore it is not surprise that the novel COVID-19 virus would also cause anosmia in infected patients. There have been a large number of reports of a major increase in the number of patients presenting with anosmia with or absence of other symptoms. This has been widely shared on medical discussion boards by physicians from all over the world managing a surprisingly high rate of cases. Mostly physicians assume that these patients may be some of the previously hidden carriers or proteins that have facilitated the rapid spread of COVID-19 $[6,7]$.

The pathogenesis of anosmia related to SARSCoV-2 has not been defined and most studies have shown that COVID-19-related olfactory dysfunction demonstrates distinct characteristics differentiating it from post-viral olfactory loss related to other viral causes [8]. The olfactory loss is of sudden onset, usually profound, and comes early in the disease process.

\section{OBJECTIVES}

To find out the association of Anosmia and Ageusia with COVID-19

To find out relationship of Gender with Anosmia and Ageusia in COVID-19 or other URTI

\section{MATERIALS AND METHODS}

Study Design: I was a cross sectional study

Settings: participants were from $\mathrm{CMH}$, Multan, Hospitals from different cities of the province of Punjab, Pakistan

Duration: the study was conducted from $1^{\text {st }}$ July to $31^{\text {st }}$ August 2021
Sample size: 185 faculty members and Medical Students of CMH Bahawalpur

\section{Inclusion Criteria}

All faculty members and Medical Students who completely filled the questionnaire and send their COVIR-19 report

\section{Exclusion Criteria}

Non-faculty members and hospital patients and those who are not who completely filled the questionnaire and not send their COVIR-19 report.

Data collection procedure: the online questionnaire self-design Performa in google document format was formulated. 4 questions were related to the basic characteristics of participants (name, age, address. designation) and 10 questions were about sign and symptoms of Covid-19.

Categorically variables were represented as frequency and percentage, while quantitative variables were shown as mean $\pm \mathrm{SD}$.

\section{METHODOLOGY}

All participants had been diagnosed via a reverse-transcription-polymerase chain reaction (RTPRC). Two call attempts for each participant were made. Olfactory or/and gustatory disorders before covid-19 and congenital disorders were also exclusive criteria. All participants provide verbal consent before fill the Performa.

Part 1: Socio-demographic characteristics like the gender, status, age and address etc.

Part 2: A self-designed Performa to assess the health of individuals like, H/O fever, sore throat, cough, dyspnea, body aches, abdominal symptoms, H/O Asthma, Allergy, PCR reports and status of vaccination are observed

\section{Participants}

We create the Performa for collect all the necessary information. All students and faculty members of $\mathrm{CMH}$ Bahawalpur are invited. Before taking part in the study, informed consent was taken to all respondents only willing participants were proceeding further.

\section{STATISTICAL ANALYSIS}

Data were analyzed with IBM SPSS Statistics for window version 25.0 (IBM Corp., Armonk, NK, USA). Descriptive statistic was obtained; continuous variables are as pressed as means with standard deviation, while categories variables are presented as per Frequencies (Percentages). 
Ghazanfar Ali et al., Haya Saudi J Life Sci, Jan, 2022; 7(1): 24-28

\section{RESULT}

We contacted 230 patients. Forty were not respond, five patients fill incomplete Performa. As Fig \# 1 shows, the study cohort consisted of 185 participants out of this $99(53.5 \%)$ were male and 86 $(46.5 \%)$ were female. The mean age was $23.93 \pm$ 6.661years.

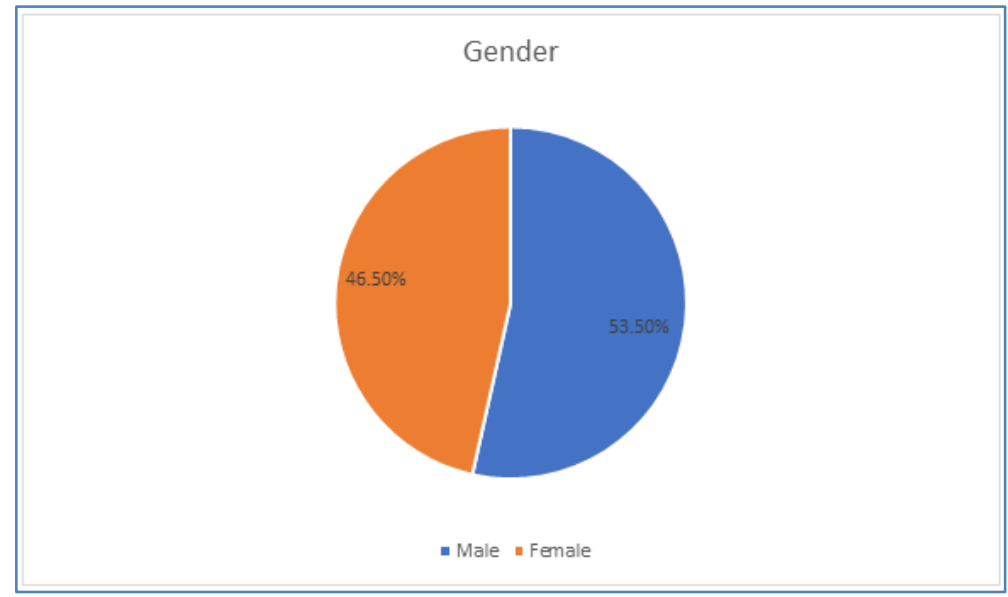

Fig-1

Table-1: Pearson Correlations of loss of taste, loss of small and PCR diagnosed Covid-19 disease

\begin{tabular}{|l|l|l|l|}
\hline & loss of taste & loss of small & diagnosed covid \\
\hline loss of taste & 1 & $.533^{* *}$ & -.079 \\
\hline loss of small & $.533^{* *}$ & 1 & -.022 \\
\hline diagnosed covid-19 & -.079 & -.022 & 1 \\
\hline$* *$ Correlation is significant at the 0.01 level (2-tailed). \\
\hline
\end{tabular}

The main hypothesis of this study to find out the association between covid-19 diagnosed case and loss of smell and taste. As in table \# 1 shows, Pearson correlation of covid-19 with loss of smell is 0.533 which is in between 0 and 1 but it has (**) which shows that there is strong positive relationship between them.

Table-2: ANOVA

\begin{tabular}{|c|c|c|c|c|c|c|}
\hline & & $\begin{array}{l}\text { Sum of } \\
\text { Squares }\end{array}$ & df & Mean Square & $\mathbf{F}$ & Sig. \\
\hline \multirow[t]{3}{*}{ loss of taste } & Between Groups & .001 & 1 & .001 & .016 & .900 \\
\hline & Within Groups & 8.561 & 183 & .047 & & \\
\hline & Total & 8.562 & 184 & & & \\
\hline \multirow[t]{3}{*}{ loss of small } & Between Groups & .014 & 1 & .014 & .310 & .578 \\
\hline & Within Groups & 8.548 & 183 & .047 & & \\
\hline & Total & 8.562 & 184 & & & \\
\hline \multirow[t]{3}{*}{ fever } & Between Groups & 2.110 & 1 & 2.110 & 9.504 & .002 \\
\hline & Within Groups & 40.625 & 183 & .222 & & \\
\hline & Total & 42.735 & 184 & & & \\
\hline \multirow{3}{*}{$\begin{array}{l}\text { upper respiratory } \\
\text { tract infection }\end{array}$} & Between Groups & .065 & 1 & .065 & .414 & .521 \\
\hline & Within Groups & 28.929 & 183 & .158 & & \\
\hline & Total & 28.995 & 184 & & & \\
\hline \multirow[t]{3}{*}{ Dyspnoea } & Between Groups & .120 & 1 & .120 & 2.354 & .127 \\
\hline & Within Groups & 9.339 & 183 & .051 & & \\
\hline & Total & 9.459 & 184 & & & \\
\hline \multirow[t]{3}{*}{ acute dry cough } & Between Groups & .323 & 1 & .323 & 1.393 & .239 \\
\hline & Within Groups & 42.412 & 183 & .232 & & \\
\hline & Total & 42.735 & 184 & & & \\
\hline \multirow[t]{3}{*}{ body aches } & Between Groups & .212 & 1 & .212 & 1.479 & .226 \\
\hline & Within Groups & 26.253 & 183 & .143 & & \\
\hline & Total & 26.465 & 184 & & & \\
\hline
\end{tabular}


Ghazanfar Ali et al., Haya Saudi J Life Sci, Jan, 2022; 7(1): 24-28

As the table \# 2 shows, among all the sign and symptoms, fever sig. is 0.002 which is near to 0.05 and have shown highly significance with sign and symptoms of covid-19. Upper respiratory tract infection also shows some association with covid-19 but other sign and symptoms like dyspnoea, dry cough not shown any significance with covid-19.

Table-3: Frequency and percentages of different sign and symptoms of suspected covid-19 patients

\begin{tabular}{|l|l|l|}
\hline Clinical Symptoms & $\begin{array}{l}\text { Frequency } \\
\text { N }\end{array}$ & $\begin{array}{l}\text { Percentage } \\
\text { \% }\end{array}$ \\
\hline Loss Of Taste & 176 & 95.1 \\
\hline Body Aches & 153 & 82.7 \\
\hline Loss Of Small & 176 & 95.1 \\
\hline Dyspnoea & 175 & 94.6 \\
\hline Acute Dry Cough & 67 & 36.2 \\
\hline Upper Respiratory Tract Infection & 36 & 19.5 \\
\hline Fever & 67 & 36.2 \\
\hline
\end{tabular}

Clinical symptoms along with covid -19 as a table 3 shows majority of participants are suffering in taste and smell loss $(95.1 \%)$ along with body aches $(82.7 \%)$, dyspnoea $(94.6 \%)$, acute dry cough $(36.2 \%)$, URTI (19.5\%) and fever (36.2\%). A few participants who suffered olfactory loss reported smoking, allergy, and CRS. Therefore, we did not perform a subgroup analysis regarding the olfactory recovery.

\section{DISCUSSION}

When the news of the novel Corona Virus appeared on the media, several pre-cautionary measures were taken by the WHO, CDC (Centre of Disease Control) NCOC (National Command and Operation Centre), and the governments of countries all across the globe to harness the spread of the virus [9]. This included the travel bans, strict and smart lockdowns, and closing of educational institutes and online teaching, discourage large gatherings and shutting down of various businesses centres, shopping malls and encourage the preventive measures. All this led to a complete disturbance of life, affectation not only a great economical and financial burden but also a huge emotional and psychological burden [10]. In this study we report cross sectional data from a community cohort with a new loss in their sense of smell and/or taste, body ache, dyspnoea, dry cough, fever, URTI and resolution of these symptoms both in people with positive and negative SARS-CoV-2 IgG/IgM antibodies.

Peng Zhou et al. recognized and considered the coronavirus (SARS-CoV-2) in the journal Nature on 3 February 2020[10], confirmed that SARS-CoV-2 used the same taste and smell receptors, angiotensin converting enzyme 2 (ACE2), as SARS-CoV to enter the cell and, in this study the author found only 18 cases $(9.67 \%)$ out of 186 participants who are COVID-19 positive but some cases who are COVID-19 negative and they are also experience the same loss of teste and small symptoms. Pathogenesis of anosmia related to COVID-19 is unknown. In our study, 176 cases (95.1\%) had both anosmia and dysgeusia; however, with anosmia presented due to the nasal obstruction. Furthermore, there were no statistically significant differences for nasal obstruction between patients with or without anosmia. This led us to suspicious another pathogenesis for anosmia than a nasal congestion with nasal obstruction. In addition, anosmia during a viral rhinitis with nasal obstruction is usually resolved within few days [7]. Due to the worldwide trend for tests for to identify patients infected with COVID-19, health strategies are severely hindered by the lack of tests that can guide the correct and immediate quarantine of positive or suspected cases of SARS-CoV-2 [1].

It is proved in many studies that the loss of smell/ taste associated with COVID-19 has been frequently complaint associated with fever, cough and body aches, mainly identified when evaluated through PCR [2, 11], our study strongly supports and shows more than $95.1 \%$ patients shows loss of smell, taste and dyspnoea. But not more association with cough, URTI and fever. We found in another research that the $41 \%$ and $38 \%$ of diagnostic-confirmed patients with COVID19 infection presented with olfactory or gustatory dysfunctions, respectively [5]. It is slightly denying our results. The role of fever in COVID-19 has not been studied in large studies. In our review of the literature, few studies have related the temperature or fever to the effects of the COVID-19 patients. As our study results shows in table \#2, the most common sign and symptom of covid-19[12] Click or tap here to enter text.

According to the WHO report, the majority of affected with COVID-19 have uncomplicated or mild illness, some patients will develop severe illness requiring oxygen therapy (14\%) and approximately 5\% will require intensive care unit treatment. Of those seriously ill, most will require oxygen support or ventilation [9]. The most common diagnosis in severe COVID-19 patients is severe pneumonia. Our study results show only $19.5 \%$ participants with URTI and $36.2 \%$ with dry cough, no any case is seen with sever pneumonia. 
Ghazanfar Ali et al., Haya Saudi J Life Sci, Jan, 2022; 7(1): 24-28

Finally, we could not find out any relationship of Gender difference with Anosmia and Ageusia in COVID-19, male and female patients are equally affected with anosmia and Ageusia. Many other authors are also unable find out any relationship between gender and covid-19 sign and symptoms [3, 10].

\section{CONCLUSION}

Olfactory and gustatory dysfunctions represent common clinical findings in COVID-19 patients along with other sign and symptoms. Sometime patient came with only anosmia and Ageusia with negative PCR report. Otolaryngologists and head-neck surgeons must by now keep this diagnostic option in mind when evaluating cases of Ageusia and nonspecific anosmia that arose suddenly and are not associated with rhinitis symptoms.

\section{Limitation}

Some important limitations should be considered when interpreting the results from this study. The most important limitation is that this is not longitudinal, but a cross-sectional study. To study the effect of covid-19 on gender and most related sign and symptoms, a longitudinal study would be most desirable. Finally, the study was conducted at one single institute in the Bahawalpur, limiting the generalizability of the findings.

\section{ACKNOWLEDGEMENTS}

We wish to thank the participants for their valuable cooperation, especially the students and staff of $\mathrm{CMH}$ Bahawalpur.

\section{Financial Disclosure / Grant Approval}

There was no funding agency.

\section{Data Sharing Statement}

The data that support the findings of this study are available on request from the corresponding author. The data are not publicly available due to privacy or ethical restrictions.

\section{Conflict of Interest}

Authors declare no conflict of interest

\section{REFERENCES}

1. Mullol, J., Alobid, I., Mariño-Sánchez, F., Izquierdo-Domínguez, A., Marin, C., Klimek, L., ... \& Liu, Z. (2020). The loss of smell and taste in the COVID-19 outbreak: a tale of many countries. Current allergy and asthma reports, 20(10), 1-5.

2. Printza, A., Katotomichelakis, M., Valsamidis, K., Metallidis, S., Panagopoulos, P., Panopoulou, M., ... \& Constantinidis, J. (2021). Smell and Taste Loss Recovery Time in COVID-19 Patients and
Disease Severity. Journal of Clinical Medicine, 10(5), 966.

3. Agyeman, A. A., Chin, K. L., Landersdorfer, C. B., Liew, D., \& Ofori-Asenso, R. (2020, August). Smell and taste dysfunction in patients with COVID-19: a systematic review and meta-analysis. In Mayo Clinic Proceedings (Vol. 95, No. 8, pp. 1621-1631). Elsevier.

4. Sayin, İ., Yaşar, K. K., \& Yazici, Z. M. (2020). <? covid19?> Taste and Smell Impairment in COVID19: An AAO-HNS Anosmia Reporting Tool-Based Comparative Study. Otolaryngology-Head and Neck Surgery, 163(3), 473-479.

5. Lee, Y., Min, P., Lee, S., \& Kim, S. W. (2020). Prevalence and duration of acute loss of smell or taste in COVID-19 patients. Journal of Korean medical science, 35(18).

6. Guan, W. J., Ni, Z. Y., Hu, Y., Liang, W. H., Ou, C. Q., He, J. X., ... \& Zhong, N. S. (2020). Clinical characteristics of coronavirus disease 2019 in China. New England journal of medicine, 382(18), 1708-1720.

7. Klopfenstein, T., Zahra, H., Lepiller, Q., Royer, P. Y., Toko, L., Gendrin, V., \& Zayet, S. (2020). New loss of smell and taste: Uncommon symptoms in COVID-19 patients in Nord Franche-Comte cluster, France. International Journal of Infectious Diseases, 100, 117-122.

8. Costa, K. V. T. D., \& Carnaúba, A. T. L. (2020). Smell and taste disorders: warning signs for SARSCoV-2 infection $\downarrow$. Brazilian journal of otorhinolaryngology, 86, 393-394.

9. World Health Organization. (2020). Clinical management of severe acute respiratory infection ( SARI) when COVID-19 disease is suspected: interim guidance, 13 March 2020 (No. WHO/2019-nCoV/clinical/2020.4). World Health Organization.

10. Makaronidis, J., Firman, C., Magee, C. G., Mok, J., Balogun, N., Lechner, M., ... \& Batterham, R. L. (2021). Distorted chemosensory perception and female sex associate with persistent smell and/or taste loss in people with SARS-CoV-2 antibodies: a community based cohort study investigating clinical course and resolution of acute smell and/or taste loss in people with and without SARS-CoV-2 antibodies in London, UK. BMC infectious diseases, 21(1), 1-11.

11. Loss of sense of smell as marker of COVID-19 infection.

12. Hu, B., Guo, H., Zhou, P., \& Shi, Z. L. (2020) Characteristics of SARS-CoV-2 and COVID19. Nature Reviews Microbiology, 1-14.

13. Gul, M. H., Htun, Z. M., \& Inayat, A. (2021). Role of fever and ambient temperature in COVID19. Expert Review of Respiratory Medicine, 15(2), $171-173$ 